\title{
INVESTIGASI SEDIMEN BAWAH LAUT MENGGUNAKAN SURVEY SEISMIK REFLEKSI DANGKAL: STUDI PENGEMBANGAN LAPANGAN ENDAPAN TIMAH PLASER
}

\author{
Wahyu Vian Pratama ${ }^{1)}$ dan Nomensen Ricardo Marbun ${ }^{1)}$ \\ ${ }^{1)}$ PT. TIMAH Tbk.
}

\begin{abstract}
ABSTRAK
Sejak 200 tahun yang lalu timah plaser telah dieksplorasi dan diproduksi di Indonesia. Studi pengembangan lapangan pada endapan timah plaser perlu dilakukan untuk mengetahui apakah masih ada potensi keterdapatan bijih timah pada lapangan-lapangan yang sudah berproduksi. Adanya lubang bor eksplorasi yang tidak menyentuh kong dan proses penambangan yang tidak mencapai batas bawah kaksa semakin memperkuat alasan studi ini dilakukan. Daerah penelitian berada di Perairan Tempilang, Bangka Barat, Provinsi Kepulauan Bangka-Belitung. Data yang digunakan dalam penelitian ini berupa 34 lintasan seismik 2D refleksi dangkal dan 9 lubang bor. Lintasan seismik dan data lubang bor diolah, dianalisis serta diinterpretasi menggunakan perangkat lunak, yang menghasilkan Sekuen A, Sekuen B, dan Sekuen C. Sekuen C diinterpretasikan sebagai geometri lembah purba yang terendapkan secara tidak selaras di atas kong, Sekuen B merupakan endapan sedimen yang terendapkan pada lingkungan transisi, dan Sekuen A menggambarkan batimetri dan kondisi dasar laut terkini. Mineral kasiterit (mineral pembawa bijih timah) terakumulasi pada Sekuen C dengan karakteristik material berupa kerikil, pasir kasar hingga pasir halus. Berdasarkan data lubang bor, urutan pengendapan sedimen secara vertikal menunjukkan karakter menghalus ke atas sebagai indikasi pendalaman lingkungan pengendapan. Berdasarkan hasil interpretasi seismik dan data lubang bor diketahui bahwa terdapat lembah berupa alur sungai purba pada bagian timur Blok B di daerah penelitian yang diduga masih berpotensi menghasilkan bijih timah dan belum diproduksi sampai saat ini. Alur sungai tersebut memiliki orientasi relatif baratdaya-timurlaut yang merupakan kemenerusan percabangan sungai purba utama. Ketebalan sedimen plaser di Perairan Tempilang yang berpotensi menghasilkan bijih timah berkisar antara 520 milidetik.
\end{abstract}

Kata Kunci: timah, plaser, seismik, tempilang dan sungai purba.

\begin{abstract}
Since 200 years ago tin placer had been explored and produced in Indonesia. The field development studies on tin placer deposits need to be carried out to determine whether the area still have potential or not. The two reasons why this study conducted are the existence of some exploration drill hole that does not reach basement (kong) and the mining process that does not reach the bottom limit of ore (kaksa). The research area is located in Tempilang Waters, West Bangka, Bangka Islands. Data that used in this study are 34 two dimension (2D) shallow reflection seismic and 9 drill holes. Seismic lines and drill hole data were processed geophisically, analyzed and interpreted geologically. Those produce three main horizons consisting of Sequence A, Sequence B, and Sequence C. Sequence C is interpreted as ancient valley geometry, Sequence B is the sediment layer that deposited in transitional zone and Sequence A describes as bathymetry. Cassiterite mineral (tin-bearing mineral) are accumulated at Sequence $C$ with ore characteristics consist of gravel, coarse to fine sand sediment. Furthermore, from the bore hole data it can be seen that vertical succession shows deepening upward and fining upward. Based on seismic interpretation and borehole data it has been known that there are valley in the form of ancient channel path which are potentially contain tin ore and have not been produced untill now. The channel orientation has relatively northeast-southwest which is the continuity of branching of main
\end{abstract}


ancient channel. Finally, the thickness of the potentially tin placer sediment in the Tempilang Waters ranges from 5-10 milliseconds.

Keywords: tin, placer, seismic, tempilang, and ancient channel

\section{A. PENDAHULUAN}

\section{A.1. Latar Belakang}

Sejak 200 tahun yang lalu bijih timah telah dieksplorasi dan diproduksi di Indonesia. PT Timah Tbk merupakan salah satu perusahaan yang memiliki komoditas mineral utama timah dengan ruang lingkup usaha mencakup dari hulu ke hilir. Izin Usaha Pertambangan (IUP) PT Timah Tbk meliputi Pulau Bangka, Pulau Belitung dan Kepulauan Riau (Pulau Kundur). Luas seluruh IUP yang dimiliki oleh PT Timah Tbk sekitar 428.203,98 Ha dengan jumlah 119 IUP. Proses eksplorasi mineral logam timah harus dilakukan secara berkelanjutan untuk peningkatan jumlah sumberdaya dan cadangan. Studi pengembangan lapangan ini perlu dilakukan untuk mengetahui apakah masih ada potensi keterdapatan bijih timah pada lapangan-lapangan yang sudah berproduksi. Adanya lubang bor eksplorasi yang tidak menyentuh "kong" dan proses penambangan yang tidak mencapai batas bawah "kaksa" semakin memperkuat alasan studi ini perlu dilakukan.

Lokasi penelitian berada di Perairan Tempilang, Kabupaten Bangka Barat, Provinsi Kepulauan Bangka-Belitung. Daerah Tempilang dapat ditempuh menggunakan jalur darat dari Kota Pangkalpinang dengan waktu tempuh \pm 2 jam. Jarak area studi dari dermaga terdekat sejauh $2,5 \mathrm{~km}$ dengan menggunakan transportasi laut. Penelitian ini bertujuan untuk mengevaluasi apakah masih terdapat potensi cadangan bijih timah pada lapangan-lapangan yang telah berproduksi. Selain itu, studi ini juga bertujuan untuk memaksimalkan lokasi-lokasi berstatus brown field.

\section{A.2. Regional Geologi}

Kepulauan Bangka Belitung merupakan bagian dari Sabuk Timah Asia Tenggara (Southeast Asia Tin Belt) yang membentang sepanjang $3.000 \mathrm{~km}$ dari Myanmar melalui Thailand, Semenanjung Malaya, hingga Kepulauan Riau dan Kepulauan Bangka Belitung di Indonesia (Gambar 1).

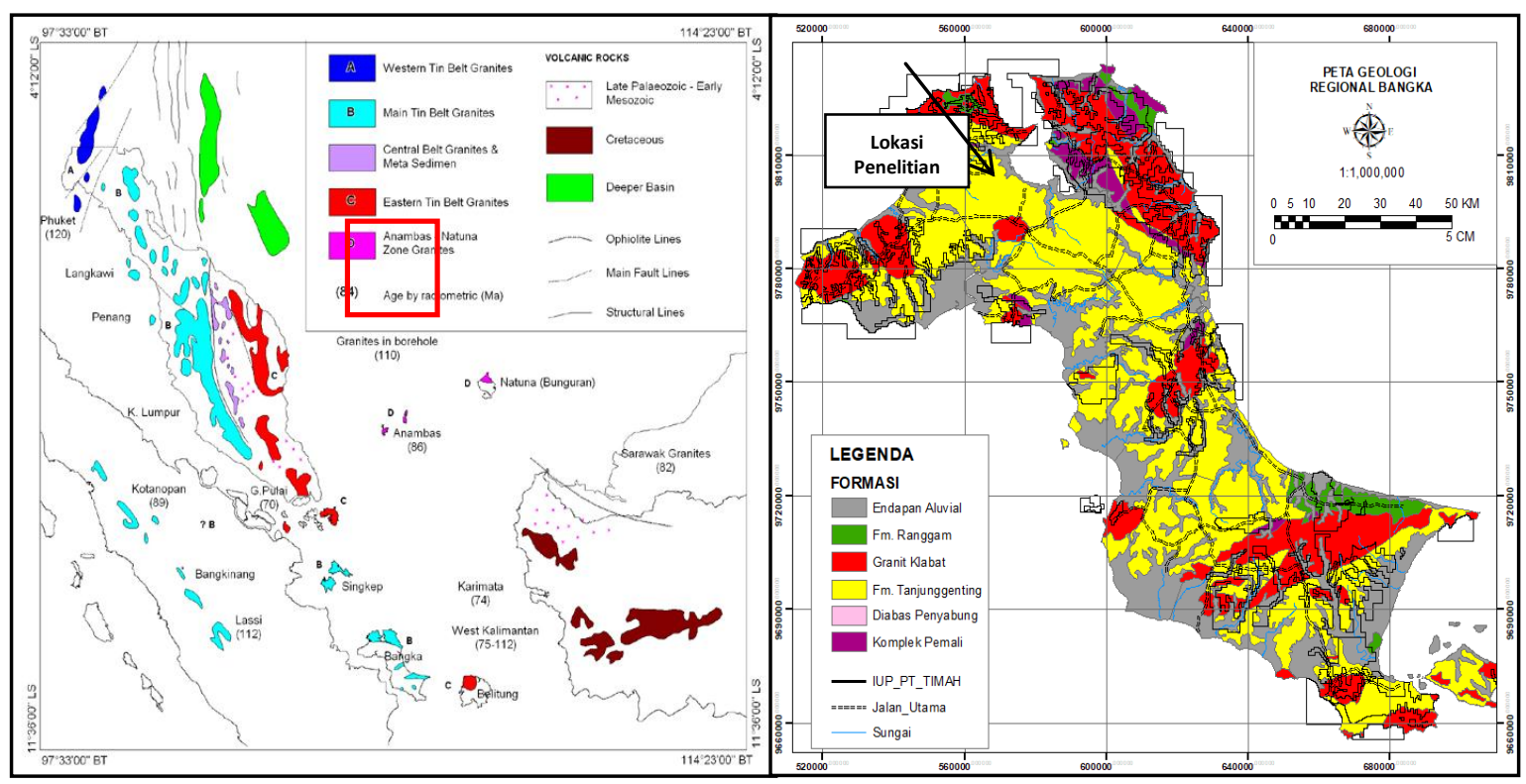

Gambar 1. Jalur timah regional (Batchelor, 1983) (Kiri) dan Peta Geologi Lembar Bangka Utara (Andi Mangga \& Djamal, 1994) dan Bangka Selatan (Margono dkk, 1995) (Kanan) 
Sabuk Timah tersebut merupakan produk dari rentetan intrusi batuan granitik yang terbentuk pada tepian Kraton Sunda Inti pada Zaman Jurasik. Keberadaan mineralisasi timah pada Sabuk Timah ini dikontrol oleh kombinasi antara sejarah tektonik, tipe intrusi granitik, tipe mineralisasi primer dan proses erosi-sedimentasi pada Era Kenozoik Akhir yang menjadi pengontrol utama mineralisasi sekunder yang menjadi target eksplorasi di daerah penelitian.

Daerah studi masuk ke dalam Peta Geologi Lembar Bangka Utara. Andi Mangga dan Djamal (1994) menjelaskan bahwa stratigrafi daratan Bangka Utara yang tertua dimulai dari pembentukan Kompleks Malihan Pemali (berumur Permo-Karbon) terdiri atas sekis dan filit dengan sisipan kuarsit dan batugamping. Secara tidak selaras di atasnya terendapkan Formasi Tanjung Genting (berumur Trias Awal) yang terdiri dari metabatupasir, batupasir, batupasir lempungan dan batulempung. Kedua formasi tersebut diterobos oleh Diabas Penyabung (berumur Perm-Trias Awal) yang umumnya berupa dike, dan Granit Klabat (berumur Trias Akhir) yang terdiri dari granit, granodiorit, adamelit, diorit kuarsa dan korok aplit. Dari Zaman Trias sampai Tersier Akhir pulau Bangka diduga berada pada daerah tinggian sehingga pada zaman tersebut tidak terjadi proses sedimentasi. Barulah pada Kala Plio-Pleistosen di atasnya terendapkan secara tidak selaras Formasi Ranggam yang terdiri dari lempung tufaan, dengan sisipan tipis lanau dan gambut. Sebagai satuan termuda adalah endapan sedimen kuarter yang terendapakan secara tidak selaras di atas seluruh formasi yang ada yang terdiri Endapan Pasir Kuarsa, Endapan Rawa, dan Endapan Aluvial (Gambar 2).

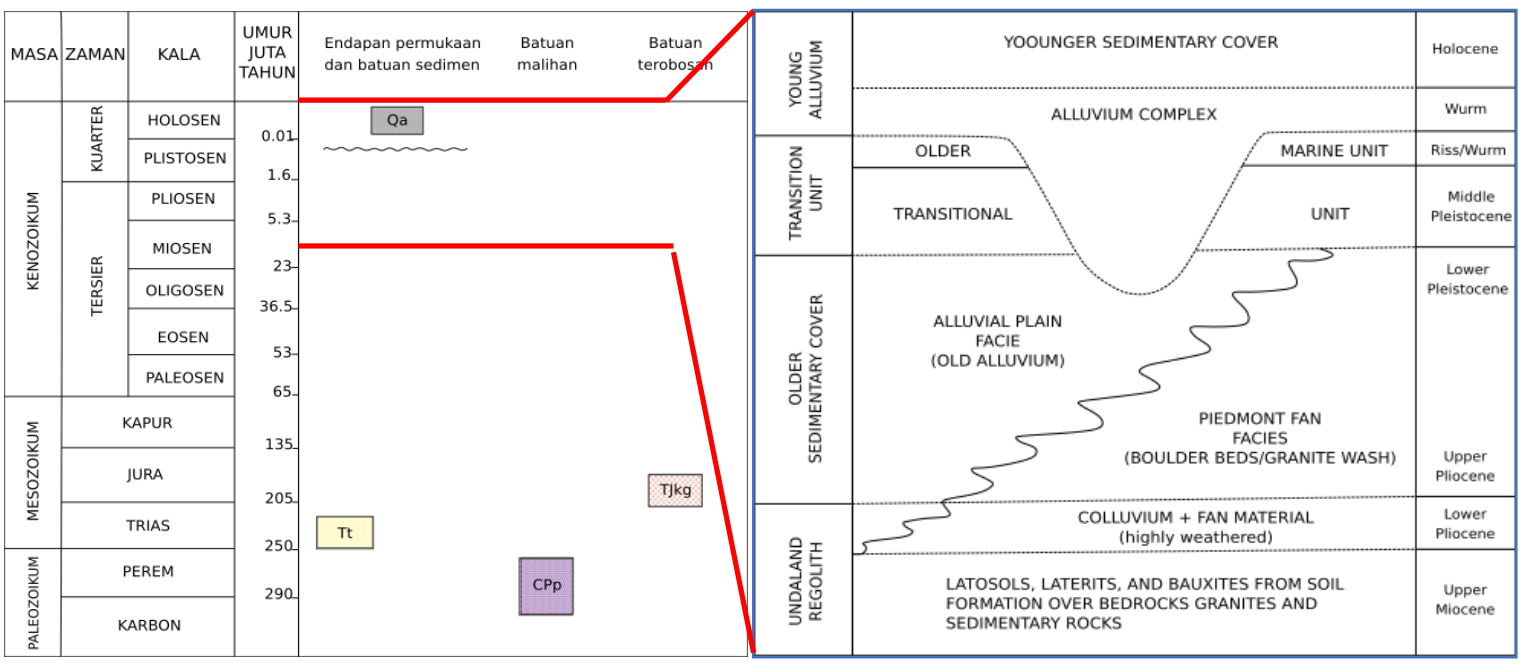

Gambar 2. Kesebandingan kolom stratigrafi regional Bangka Utara (Andi Mangga \& Djamal, 1994) (Kiri) dengan suksesi endapan sedimen aluvial pulau Bangka (Batchelor, 1979) (Kanan)

Suksesi endapan sedimen aluvium pada Pulau Bangka telah dideskripsikan secara detail oleh Batchelor (1979) (Gambar 2). Pengendapan plaser timah di Pulau Bangka diperkirakan terjadi semenjak Miosen - Awal Pliosen pada saat kondisi iklim semi-ardi dan ketinggian muka air laut berada di bawah continental slope margin dari Paparan Sunda. Pada saat itu, terjadi pelapukan lateritik dari endapan-endapan timah primer sehingga terbentuk endapan timah yang didominasi oleh endapan eluvial dan koluvial (dominasi kaksa autochtonous). Curah hujan yang tinggi pada Akhir Pliosen menghasilkan endapan memicu proses transportasi aliran debris yang menghasilkan endapan plaser dengan pelamparan yang sedikit lebih jauh dari batuan sumber (dominasi kaksa allochtonous). Proses presipitasi yang terus meningkat hingga Awal Pleistosen menyebabkan terjadi perombakan endapan aluvial yang lebih tua oleh aliran-aliran sungai teranyam menghasilkan endapan-endapan plaser rombakan dengan pelamparan yang lebih luas lagi dan terkontrol oleh pola aliran sungai teranyam (dominasi "mincan"). Proses transgresi terakhir pada 
Holosen menghasilkan endapan-endapan plaser rombakan yang banyak ditemukan di daerah terasteras sungai dan tepian pantai (didominasi oleh timah kulit).

Struktur geologi berupa sesar naik dan mendatar, serta lipatan yang mempunyai variasi arah dari barat laut-tenggara, timur laut-barat daya, hingga utara-selatan. Struktur geologi ini umumnya memotong batuan tertua dan sedimen di atasnya. Kegiatan tektonik di daerah Bangka Utara dimulai pada Zaman Perm yang dicirikan dengan kehadiran batuan malihan. Kemudian pada Perm-Trias terbentuk deformasi pertama yang dicirikan oleh intrusi Diabas Penyabung dengan arah deformasi timur laut- barat daya dan disusul oleh proses sedimentasi yang membentuk Formasi Tanjung Genting. Pada Zaman Trias Atas-Jura berlangsung deformasi kedua yang ditandai dengan dike-dike Granit Klabat. Barulah pada Zaman Kapur berlangsung deformasi ketiga dengan arah tegasan utara-selatan. Hal ini dapat dilihat dari arah sesar-sesar mendatar pada Pulau Bangka yang relatif berarah baratlaut-tenggara dan baratdaya-timurlaut. Setelah mengalami proses-proses tersebut di atas, daerah Bangka Utara menunjukkan kestabilan sampai sekarang.

\section{B. METODOLOGI PENELITIAN}

Pada studi ini metode yang digunakan adalah metode geofisika yaitu metode seismik refleksi dangkal (Gambar 3). Pemetaan struktur bawah permukaan menggunakan metode seismik dilakukan dengan memberikan energi gelombang ke dalam bumi dan menganalisis hasil pantulannya. Metode seismik merupakan metode geofisika yang sering digunakan dalam mencitrakan kondisi bawah permukaan bumi dengan menggunakan prinsip perambatan gelombang mekanik. Cepat rambat gelombang seismik tergantung pada sifat-sifat elastik dari mineral-mineral penyusun batuan. Batupasir, batulempung, dan berbagai jenis batulempung lunak yang terbentuk oleh komplek poripori yang berisi fluida atau tipe-tipe material padat yang lebih lunak seperti lempung, cepat rambat gelombangnya sangat tergantung pada porositas dan material pengisinya. Dalam metode seismik, getaran yang ditimbulkan dekat permukaan bumi akan dipantulkan terus oleh bidang pantul diantara bidang perlapisan batuan dalam kerak bumi. Rekaman waktu pantul di permukaan ditampilkan dalam bentuk skala waktu.

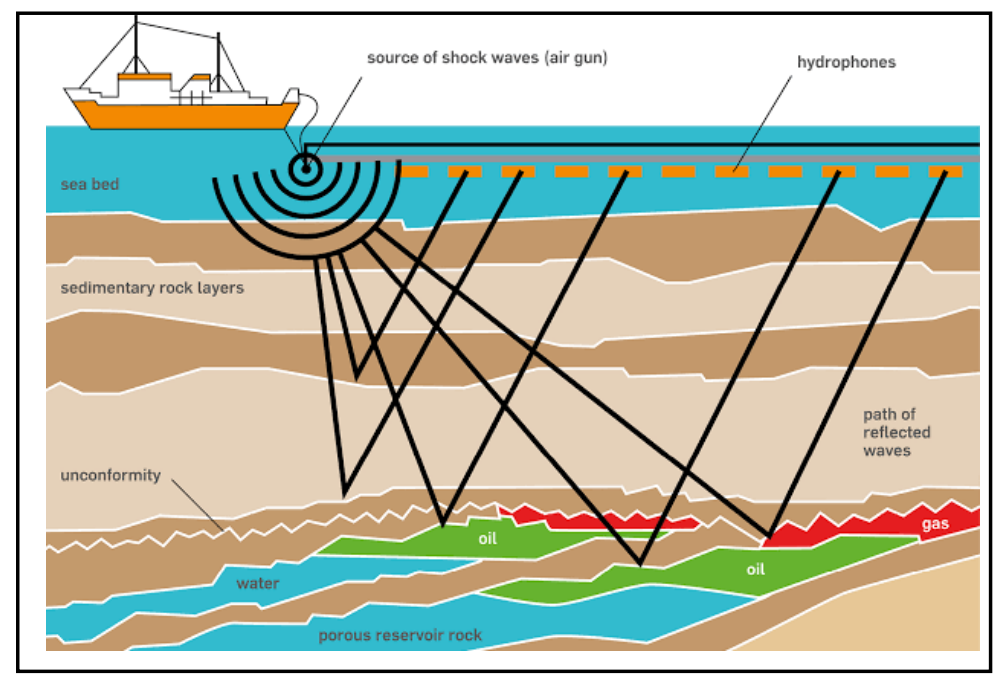

Gambar 3. Prinsip Kerja Perekaman Seismik di Laut (Sumber: portonews.com)

Secara umum, prinsip kerja seismik pantul dangkal saluran tunggal adalah menggunakan gelombang akustik yang ditimbulkan oleh sumber suara boomer yang dikirim ke bawah permukaan laut dan akan bergerak menembus lapisan sedimen. Sebagian dari gelombang ini akan dipantulkan kembali ke permukaan yang ditangkap oleh hydrophone dan sebagian lainnya menembus lapisan berikutnya untuk kemudian dipantulkan kembali ke atas. Sinyal yang ditangkap oleh hydrophone 
direkam secara digital, yang dapat diinterpretasikan sebagai batas perlapisan akibat perbedaan densitas lapisan dalam bentuk penampang seismik.

\section{HASIL DAN PEMBAHASAN}

\section{C.1. Penampang Profil Bor Vertikal (TMP-09)}

Lubang bor TMP-09 digunakan sebagai key well untuk interpretasi penyebaran lateral endapan. TMP-09 berisi informasi urutan vertikal endapan dan informasi mengenai kandungan/ kadar mineral bijih timah pada blok B. Berdasarkan urutan vertikal, secara umum endapan dibagi menjadi 2 (dua) perulangan pengendapan berpola fining upward yaitu FU-1 dan FU-2. FU-1 terendapkan lebih dahulu dibandingkan FU-2 (Gambar 4).

Endapan FU-1 terdiri dari endapan menghalus ke atas (fining upward) kerikil, pasir, pasir lempungan, lempung pasir hingga lempung. Perubahan ukuran sedimen yang semakin menghalus ke atas mengindikasikan adanya kenaikan muka air laut pada saat pengendapan berlangsung. Kenaikan muka air-laut menyebabkan terjadinya perubahan lingkungan pengendapan. Dalam hal ini, bagian bawah endapan FU-1 terendapkan pada lingkungan darat (teresterial) dan ke arah sedimen halus (lempung pasiran - lempung) lingkungan berubah menjadi lingkungan transisi. Lingkungan pengendapan darat berasosiasi dengan keberadaan mineral bijih timah.

Endapan FU-2 merupakan perulangan endapan pola fining upward: endapan pasir, lempung pasiran menghalus hingga endapan lempung. Endapan pasir pada FU-2 terendapkan pada lingkungan transisi sebagai lanjutan pengendapan dari endapan lempung sebelumnya (FU-1). Kondisi kenaikan muka air laut semakin intensif, menyebabkan lingkungan transisi berubah menjadi lingkungan laut yang dicirikan oleh kehadiran lempung yang tebal pada bagian atas profil bor TMP-09. Endapan pasir pada FU-2 tidak berasosiasi dengan keberadaan endapan bijih timah. Lingkungan transisi memiliki peluang yang kecil untuk membentuk cebakan mineral bijih timah.

\section{C.2. Interpretasi Seismik}

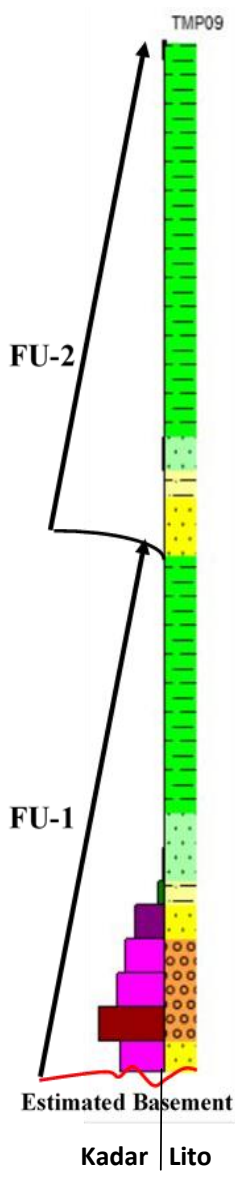

Gambar 4. Penampang Profil Bor TMP09

Secara umum lintasan survei terdiri dari 34 lintasan memanjang arah barat - timur dengan interval antar lintasan sejauh 40 meter. Area survei seismik dilakukan pada Blok B dengan total panjang lintasan mencapai $40 \mathrm{~km}$ (Gambar 5)

Berdasarkan analisis dan interpretasi seismik diketahui bahwa terdapat 3 sekuen seismik yang terdiri dari Sekuen A, Sekuen B, dan Sekuen C. Sekuen C terendapkan secara tidak selaras di atas batuan dasar dengan batas erosi yang jelas dan menunjukkan geometri channel. Sekuen $\mathrm{C}$ yang membentuk menyerupai lembah/alur purba ini diduga sebagai fasies pengisian alur berupa onlap fill hasil fluviatil (warna kuning pada Gambar 6). Sekuen C mempunyai konfigurasi pantulan sub paralel-kaotik dengan amplitudo sedang-lemah dan tidak menerus. Selain itu, sekuen ini dicirikan dengan reflektor yang bersifat onlap. Internal reflektor ini diinterpretasikan sebagai endapan sedimen yang disusun oleh material berbutir pasir kasar-lempung dan kemungkinan besar merupakan hasil dari endapan fluvial dan diendapkan di lingkungan terrestrial. Sekuen C mengerosi batuan di bawahnya yang diduga merupakan batuan dasar seperti Formasi Tanjunggenting atau Formasi Pemali. 


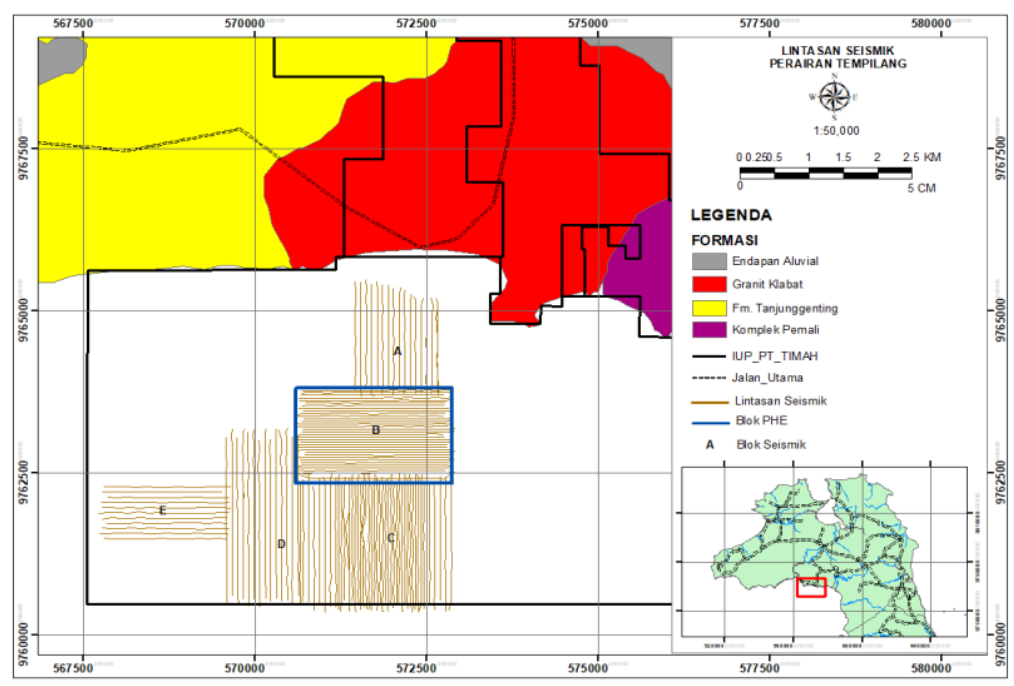

Gambar 5. Lintasan seismik 2D pada lokasi survei

Sekuen B diendapkan secara tidak selaras di atas Sekuen C dengan batas sekuen sebagai pepat erosi (erosional truncation) (warna hijau muda pada Gambar 6). Setempat pada Top Sekuen B diamati lembah/alur purba yang juga diduga sebagai fasies pengisian alur berupa onlap fill hasil fluviatil, namun memiliki geometri yang lebih kecil dari Sekuen $\mathrm{C}$ dan hanya ditemukan di beberapa lokasi saja. Hal ini menunjukkan dominasi sungai pada umur tersebut sudah mulai berkurang dan menunjukkan perubahan lingkungan pengendapan menuju zona transisi. Bagian atas Sekuen B dicirikan oleh internal reflektor paralel dengan amplitudo kuat dan menerus. Bagian bawahnya memiliki konfigurasi reflektor subparalel-transparan dengan amplitudo sedang. Reflektor tersebut ditafsirkan sebagai fraksi sedimen berbutir sedang (pasir), pasir lempungan dan pasir kasar dengan ketebalan berkisar 5-10m. Sekuen ini, berdasarkan posisinya, diduga terendapkan pada lingkungan darat-transisi dan berenergi kuat-sedang.

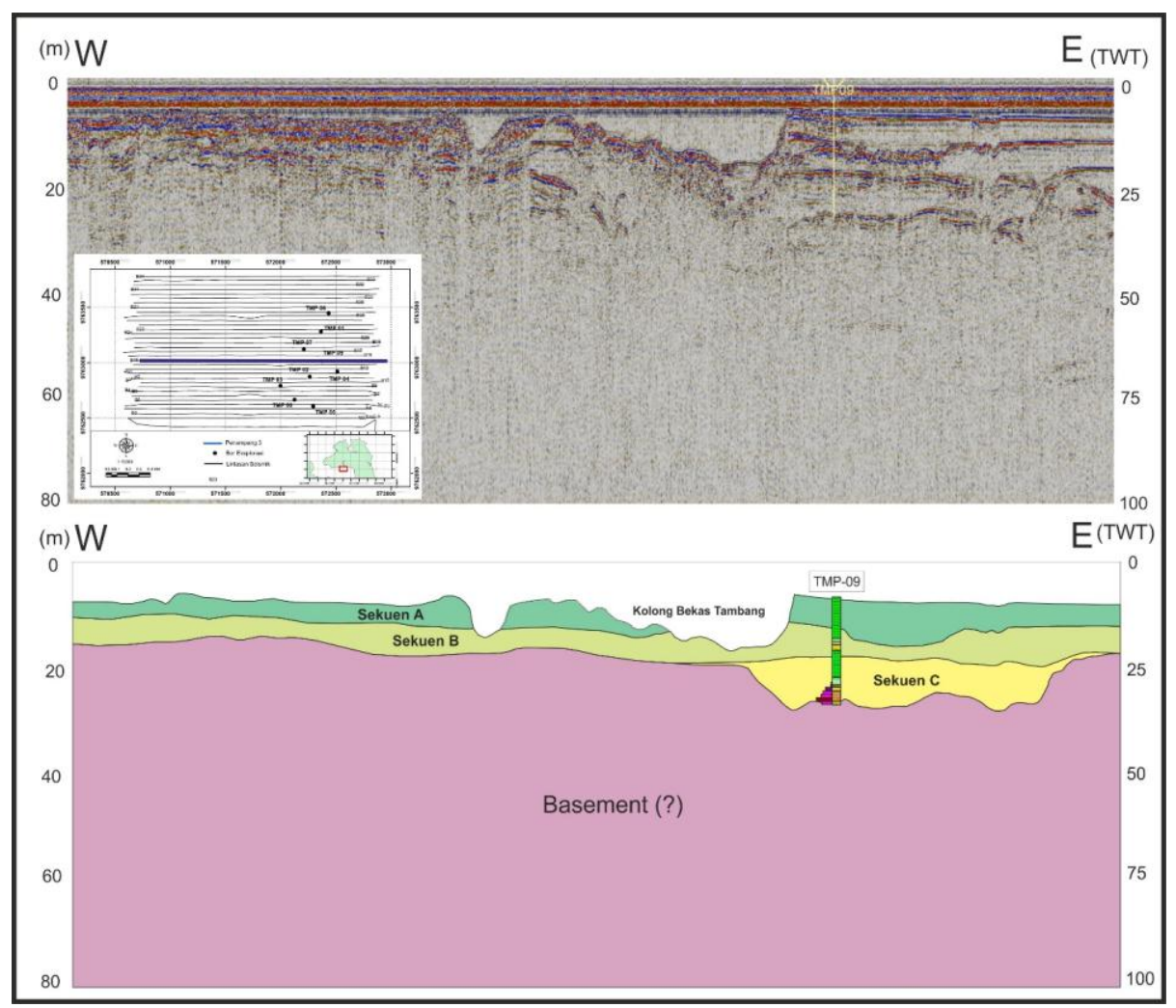

Gambar 6. Interpretasi seismik lintasan B15 pada Blok B Tempilang. 
Sekuen A merupakan sedimen termuda (Holosen) dan dijumpai pada seluruh lintasan seismik. Pada peta isopach, dengan asumsi kecepatan rambat gelombang Sekuen A $1600 \mathrm{~m} / \mathrm{s}$, diperoleh ketebalan lapisan berkisar dari 5-10m. Bagian atas Sekuen A dicirikan oleh karakter internal reflektor paralel dengan amplitudo kuat dan menerus (Gambar 6). Bagian bawahnya memiliki konfigurasi reflektor subparalel-transparan dengan amplitudo sedang-lemah. Internal reflektor paralel, subparalel dan transparan tersebut di atas ditafsirkan sebagai fraksi sedimen berbutir halus (pasir), lumpur (lanau +lempung) dan lempung. Pada permukaan dasar laut atau Top Sekuen A berkembang kolong/mangkuk bekas sisa penambangan (Gambar 7a). Sekuen ini diduga diendapkan pada lingkungan marin (pantai/paparan laut dangkal) dan berenergi lemah-sedang. Perubahan lingkungan pengendapan Sekuen A dari fluviatil ke pantai/paparan laut dangkal ini menandakan bahwa pada Kala Holosen setidaknya telah terjadi kenaikan muka air laut.

\section{C.3. Area Prospek - Valley Hunting}

Setelah menentukan horizon pada 34 lintasan seismik maka horizon yang sama dihubungkan dan diinterpolasi untuk membuat peta permukaan. Permukaan yang dihasilkan tersebut masih dalam domain waktu, sedangkan data yang dibutuhkan adalah dalam domain kedalaman karena setiap perhitungan yang akan dilakukan nantinya, mulai dari perhitungan geometri sungai sampai perhitungan sumberdaya dilakukan dalam domain kedalaman (meter) bukan waktu (detik). Konversi domain waktu ke domain kedalaman mengacu pada marker data sumur. Data permukaan yang masih dalam domain waktu dikonversi dengan cara mengalikannya dengan kecepatan gelombang seismik. Proses konversi ini bersamaan dengan pengikatan data sumur dengan data seismik. Setelah seismik dan data lubang bor berada dalam domain yang sama, maka horizon yang diinterpretasikan sebagai dasar sungai purba ditampalkan dengan data lubang bor. Setelah proses konversi dan pengikatan dengan data sumur selesai, maka interpolasi permukaan yang dihasilkan dari proses tersebut dapat digunakan untuk melakukan analisis cebakan bijih timah plaser. Berdasarkan interpretasi seismik dan data lubang bor eksplorasi terdahulu teramati lembahan berupa jalur sungai purba yang diduga tempat akumulasi timah plaser dan belum diproduksi sampai saat ini. Jalur sungai tersebut berarah relatif baratdaya-timurlaut. Pola alur purba pada arah tersebut dapat diamati dengan jelas pada Sekuen C (Gambar 7b).
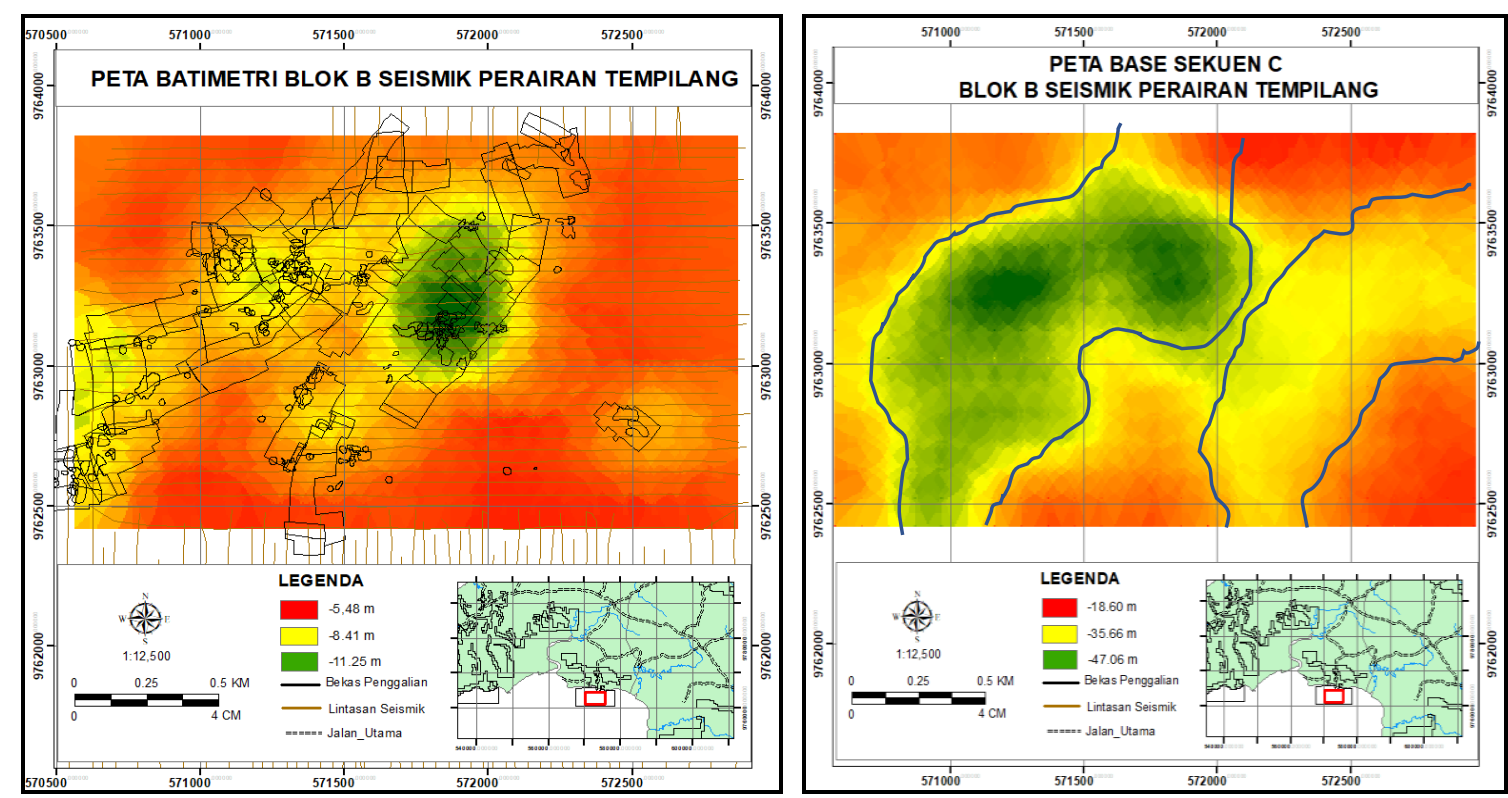

Gambar 7. (a) Peta Batimetri Blok B (Top Sekuen A) bertampalan dengan bekas kolong penggalian tambang dan (b) Peta Base Sekuen C yang menunjukkan pola aliran sungai purba.

Dari hasil pengolahan data dan analisis seismik dan data lubang bor terdahulu dapat disimpulkan bahwa pada daerah target pengembangan eksplorasi terdapat lembah purba berupa sungai atau channel dengan arah relatif baratdaya-timurlaut pada bagian timur (warna kuning pada Gambar 
7b). Dengan demikian, dapat diinterpretasikan bahwa sumber utama bijih timah berasal dari batholit granit yang berada di bagian utara blok IUP. Untuk memastikan apakah sungai purba pada arah tersebut mengandung bijih timah atau tidak, maka perlu dilakukan pengeboran pengembangan.

Pengeboran eksplorasi dilakukan pada bagian timur blok seismik B pada area seluas \pm 83 ha. Sebagian besar area blok seismik B merupakan area yang sudah ditambang. Namun berdasarkan hasil eksplorasi geofisika dan interpretasi geologi blok yang sudah ditambang, dimungkinkan ada pengembangan cebakan endapan fluvial di sebelah timur-tenggara blok tambang sehingga kegiatan pengembangan difokuskan pada area tersebut. Bor pengembangan yang dilakukan berjumlah 9 lubang bor dengan jarak antara titik bor terdekat sejauh $\pm 200 \mathrm{~m}$.

\section{C.4. Korelasi stratigrafi}

Korelasi stratigrafi dilakukan berdasarkan kesamaan fisik endapan (terutama ukuran butir sedimen) yaitu menggunakan konsep litostratigrafi. Berdasarkan data profil bor TMP-01 hingga TMP 09, endapan dikelompokkan menjadi 5 (lima) grup endapan yaitu Lempung (LPG), Lempung pasiran (LPG/PSR), Pasir lempungan (PSR/LPG), Pasir (PSR), dan Kerikil (KRK). Dengan tujuan memperkirakan geometri dan dimensi sungai purba, maka dibuat 3 penampang profil bor yaitu penampang 1 (TMP06-TMP01-TMP09-TMP02-TMP05), penampang 2 (TMP07-TMP09-TMP04) dan penampang 3 (TMP03-TMP08-TMP05) (Gambar 8).

Pola pengendapan fining upward merupakan ciri profil bor keseluruhan (TMP-01 hingga TMP-09) pada blok B Tempilang. Endapan sedimen kerikil hingga endapan pasir sebagai endapan teresterial berkembang pada bagian paling bawah profil bor. Endapan-endapan ini diperkirakan menumpang di atas basement/ kong sedimen yang diperkirakan dari Formasi Tanjung Genting. Ke arah atas penampang berkembang sedimen-sedimen halus (pasir halus hingga lempung) yang diduga berasal dari lingkungan transisi dan berakhir pada lingkungan laut dangkal. Keberadaan pasir lempungan dan lempung pasiran terjadi pada lingkungan transisi dan endapan lempung tebal di bagian paling atas terjadi pada lingkungan laut. Kenaikan muka air laut menyebabkan perubahan lingkungan pengendapan pada lokasi blok B Tempilang.

Berdasarkan korelasi antar penampang (Gambar 9), endapan sedimen kasar (pasir hingga kerikil) yang menumpangg secara tidak selaras di atas kong/basement tersebar membentuk geometri sungai/channel. Persebran pada arah Barat - Timur diinterpretasikan sebagai lebar sungai purba. Hal ini mengkonfirmasi keberadaan geometri channel yang telah diinterpretasi sebelumnya pada seismik

Batchelor (1979) membagi stratigrafi sedimen kuarter Sundaland menjadi 4 (empat) kelompok besar (tua ke muda) yaitu Sundaland Regolith, Older Sedimentary Cover, Transition Unit, dan Young Alluvium (Gambar 10). Blok B Tempilang merupakan anggota dari Young Alluvium, sedangkan kelompok lainnya tidak dijumpai pada daerah penelitian. Young Alluvium terdiri dari Alluvial Complex dan Younger Sedimentary Cover. Endapan berbutir kasar (kerikil hingga pasir) atau sekuen $\mathrm{C}$ pada penampang seismik merupakan bagian dari Alluvial Complex dan kadar mineral bijih ekonomis dijumpai pada kompleks ini, sedangkan sedimen halus (produk lingkungan transisi dan laut dangkal) atau sekuen A dan sekuan B pada seismik merupakan bagian dari Younger Sedimentary Cover dan pada endapan tersebut tidak umum dijumpai mineral bijih timah ekonomis. 

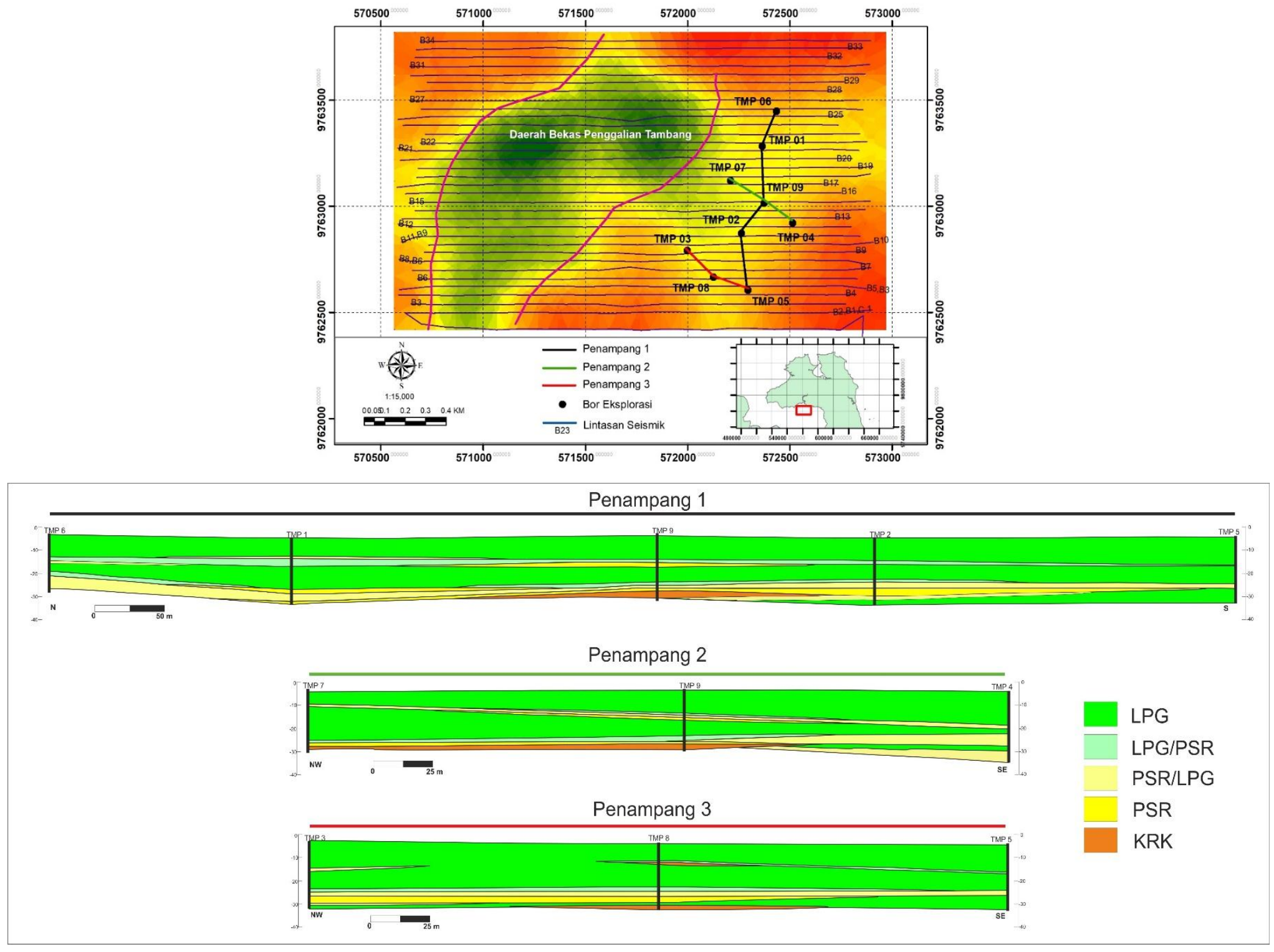

Gambar 8. Lokasi bor eksplorasi dan korelasi penampang antar lubang bor. 


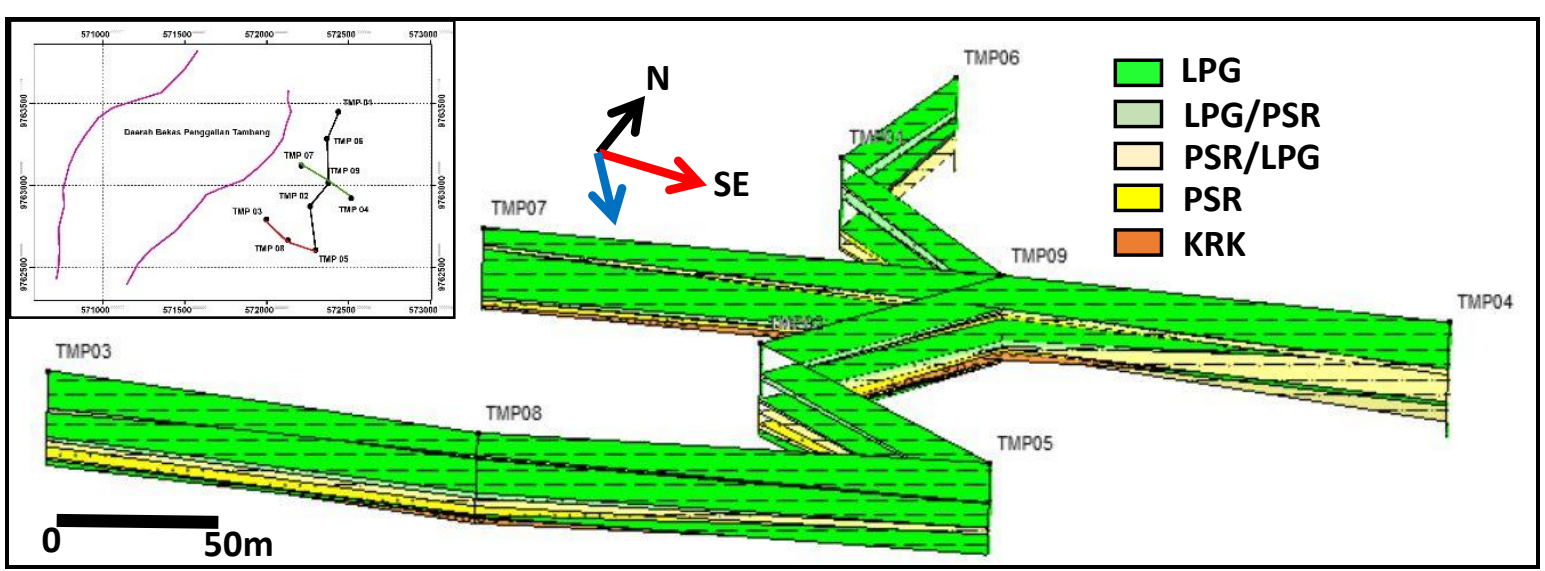

Gambar 9. Korelasi antar penampang stratigrafi.

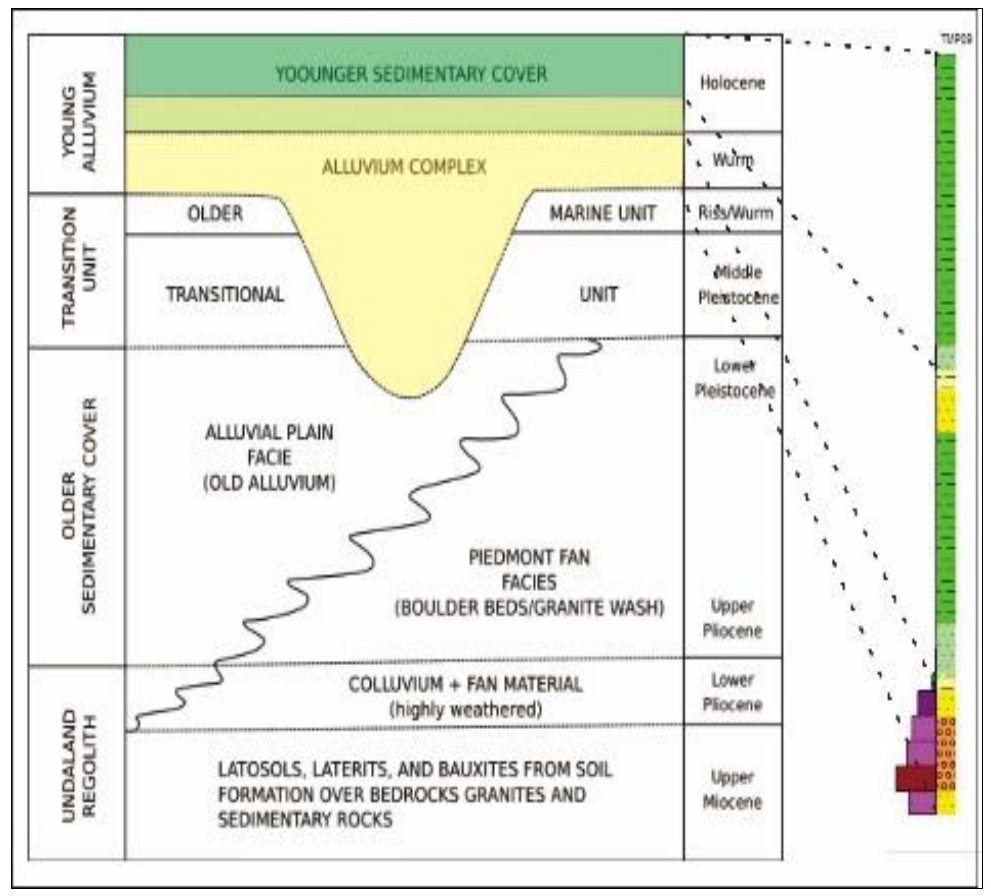

Gambar 10. Kolom kesebandingan stratigrafi endapan aluvial (modifikasi dari Batchelor 1979) dengan hasil pengeboran lubang bor TMP 09

Pola aliran sedimen diinterpretasikan berasal dari timurlaut menuju baratdaya. Sumber sedimen diduga dari host rock Pluton Tempilang (No. 04) (Gambar 11). Hal tersebut didukung dari lokasi tambang timah primer Tempilang TB-21 dan TB-22 yang berjarak sekitar $8 \mathrm{~km}$ ke arah utara daerah penelitian. Mineralisasi pada tambang primer tersebut merupakan salah satu sumber utama dari endapan timah plaser yang ditemukan di daerah peneltian. Jika aliran sedimen berasal dari timurlaut maka semakin ke arah baratdaya kemungkinan potensi keberadaan cebakan mineral bijih timah semakin kecil, mengingat jarak transportasi yang semakin jauh dari sumber. Hal ini didukung hasil interpretasi Gambar 10 bahwa sedimen kasar semakin menipis ke arah baratdaya dan sebaliknya, endapan lempung semakin tebal. Dengan demikian, eksplorasi pengembangan lapangan bijih timah plaser pada Blok B Tempilang akan dilakukan pada bagian timur Blok B (zona berwarna kuning pada Gambar 11). 


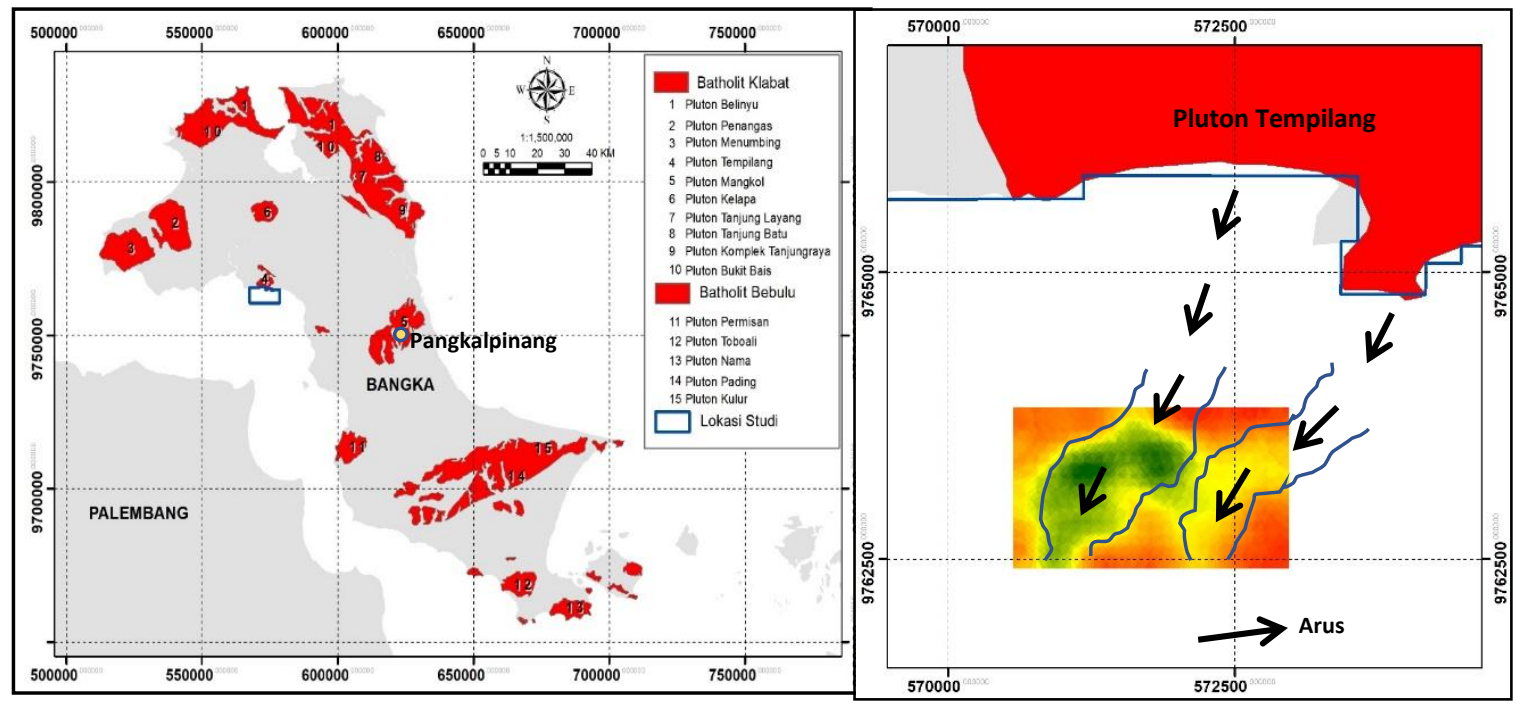

Gambar 11. Peta distribusi plutonik Pulau Bangka (modifikasi dari Cobing dan Mallick, 1984)

(Kiri) dan prediksi arus sedimentasi pada sungai purba menuju Blok B Tempilang (Kanan)

\section{KESIMPULAN}

Berdasarkan interpretasi dan analisis data lintasan seismik dan lubang bor di atas, maka dapat disimpulkan beberapa hal diantaranya:

1. Lembah purba yang diduga masih berpotensi sebagai tempat akumulasi bijih timah berada di bagian timur seismik Blok B dengan arah relatif baratdaya-timurlaut.

2. Sekuen $\mathrm{C}$ merupakan lapisan yang memiliki potensi paling tinggi sebagai tempat akumulasi bijih timah dengan ketebalan 5-20 milidetik atau 6-15 m.

3. Berdasarkan korelasi stratigrafi dan analisa sampel pengeboran, mineral bijih timah kasiterit berasosiasi dengan sedimen berbutir kasar, mulai dari kerikil hingga pasir halus.

\section{DAFTAR PUSTAKA}

Batchelor, B. C. (1979): Geological characteristics of certain coastal and offshore placers as essential guides for tin exploration in Sundaland, Southeast Asia, Buletin Geology Society of Malaysia, 11, 283-313.

Batchelor, B. C. (1983): Sundaland tin placer genesis and Late Cenozoic coastal and offshore stratigraphy in Western Malaysia and Indonesia. Disertasi Program Dokor, Universiats Malaya, 597.

Cobbing, E.J. dan Mallick, D.I.J. (1984): Southeast Asia Granite Project Preliminary Report Indonesia. Br. Geol Surv. Overseas Rep., 41.

Mangga, S.A. dan Djamal, B. (1994): Peta Geologi Lembar Bangka Utara skala 1: 250.000, Pusat Penelitian dan Pengembangan Geologi, Bandung.

Margono, U., Supandjono, R. J. B., Partoyo, E. (1995): Peta Geologi Lembar Bangka Utara sakal $1: 250.000$, Pusat Penelitian dan Pengembangan Geologi, Bandung.

Metode Seismik Refleksi, diperoleh melalui situs internet: http://www.portonews.com/2019/migasminerba/elnusa-selesaikan-survei-seismik-marine-2d-di-semenanjung-indocina/. Diunduh pada tanggal 10 September 2019. 
